\title{
APROXIMACIÓN AL URBANISMO DE LA ANTIGUA CIUDAD DE BRIGAECIUM (CONVENTUS ASTURUM) \\ THE URBANISM OF BRIGAECIUM (CONVENTUS ASTURUM): AN APPROACH
}

\author{
DAvid Martino García \\ Área de Historia Antigua \\ Departamento de Prehistoria, Historia Antigua y Arqueología \\ Universidad Complutense de Madrid \\ davidmartino@ucm.es
}

Recibido: 01/11/2017

Aceptado: 18/03/2018

RESUMEN: Se presenta una visión general sobre el estado actual de conocimientos del urbanismo de la ciudad de Brigaecium durante el final de la Edad del Hierro y la época romana altoimperial, proponiéndose a la vez nuevas hipótesis y propuestas de investigación.

PALABRAS CLAVE: Hispania romana. Astures. Edad del Hierro. Oppidum. Urbanismo romano.

ABSTRACT: This paper shows a general overview of what it is known about the urban layout of Brigaecium, from the end of the Iron Age and during the Roman period. Available data allow for some new hypotheses and future research proposals.

KEYWORDS: Roman Spain. Astures. Iron Age. Oppidum. Roman Urbanism.

-¿Ves? Allí ¡oh amigo! se descubre la ciudad, castillo o fortaleza donde debe de estar algún caballero oprimido, o alguna reina, infanta o princesa malparada, para cuyo socorro soy aquí traído.

-¿Qué diablos de ciudad, fortaleza o castillo dice vuesa merced, señor? -dijo Sancho-. ¿No echa de ver que aquéllas son aceñas que están en el río, donde se muele el trigo?

- Calla, Sancho -dijo don Quijote-; que aunque parecen aceñas, no lo son; y ya te he dicho que todas las cosas trastruecan y mudan de su ser natural los encantos. No quiero decir que las mudan de en uno en otro ser realmente, sino que lo parece,...

M. CERVANTES, Don Quijote, Parte II, cap. 29

En vísperas de la conmemoración del cuarto centenario de la muerte de Miguel de Cervantes tuve la oportunidad de presentar, en el marco de las III Jornadas 
Internacionales "Evolución de los espacios urbanos y sus territorios en el noroeste de la Península Ibérica” celebradas en Astorga ${ }^{1}$, una contribución centrada en el urbanismo de Brigaecium, una de las ciudades de los astures. En aquellos días, me vino a la mente el pasaje de la obra cumbre cervantina que encabeza estas líneas, pues efectivamente, en la actualidad, a simple vista, nada parece indicar que en el solar sobre el que se asentó esta antigua ciudad, hubiera existido nada semejante. Más bien, todo lo contrario: al aproximarnos por la fértil vega regada por los ríos Esla y Cea, en lo alto del espigón donde confluyen ambos, no se divisa más que un caserío con su arboleda y las tierras de labor que lo rodean. Por esta vez, hagamos caso al hidalgo de La Mancha que nos advierte de que las cosas no son como parecen y descubramos que bajo lo que ahora no son más que los edificios y campos de una simple explotación agraria, en tiempos antiguos se erigió toda una verdadera ciudad. Este es el fin que pretendo con las siguientes líneas, y para ello, me propongo revisar el estado de la cuestión sobre el urbanismo prerromano y romano de esta ciudad a la vez que presento nuevas hipótesis y posibles propuestas de investigación.

\section{FUENTES LITERARIAS Y EPIGRÁFICAS SOBRE BRIGAECIUM Y SU IDENTIFICACIÓN GEOGRÁFICA}

Si consideramos el panorama de escasez y parquedad de las fuentes literarias referentes a la mayoría de las antiguas ciudades de la Península Ibérica, para las que es frecuente contar sólo con una o dos referencias aisladas, el caso de Brigaecium² es realmente notable, puesto que posee un nutrido conjunto de testimonios muy variados. Por una parte, en las fuentes literarias, aparecen nombrados sus habitantes, los Brigaecini $^{3}$, en el contexto de la conquista romana de los astures a fines del siglo I a.C. y de nuevo se registran junto con su ciudad como una de las 19 ciudades de los Astures

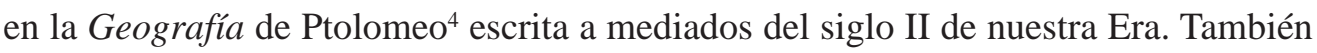
consta en los itinerarios antiguos, en varias de las rutas recogidas en el Itinerario de

\footnotetext{
1 Aprovecho para agradecer a los organizadores de este encuentro científico hispano-luso, C. Braga, F. Magalhaes y J. Ribeiro (Universidade do Minho) y R. Martínez Peñín (Universidad de León), la aceptación de esta comunicación así como su amabilidad y cordialidad durante la celebración del mismo. Este trabajo ha sido realizado en el marco del Grupo de Investigación sobre ciudades romanas (UCM-930692).

2 En este trabajo me decanto por unificar y utilizar el topónimo Brigaecium, la forma que, en virtud de la documentación literaria y epigráfica disponible, se ajusta, a mi modo de ver, mejor al que debía ser el nombre original. Entre los historiadores, eruditos y gentes de lugar es muy usual llamarla "Brigecio", forma documentada en fechas tardías y que, en cierta medida, podríamos considerar como la castellanización del topónimo antiguo.

3 Floro, 2.33.56.

$\begin{array}{lll}4 & 2.6 .29\end{array}$
} 
Antonino ${ }^{5}$ en el tardío Anónimo de Rávena ${ }^{6}$ y en una de las tablas del llamado Itinerario de Barro $^{7}$. Por otra parte, dejando al margen algunos testimonios epigráficos dudosos ${ }^{8}$, conocemos dos individuos procedentes de la ciudad en sendos epígrafes en los cuales se indicó la origo en su estructura onomástica: Alla Verina Legirnicorum Brigiaecina, en una inscripción funeraria procedente de Astorga ${ }^{9}$ y L(ucius) Fabius L(ucii) f(ilius) Silo Quir(ina tribus) Brigiaecinus, que fue honrado con un pedestal honorífico en Tarraco $^{10}$. Ambos documentos confirman el topónimo, siempre que aceptemos que el añadido de una $i$ después de la $g$ no es más que una vacilación entre Brigaecium y Brig-i-aecium; de lo contrario habría que admitir, en atención a la actual unanimidad epigráfica que el nombre correcto sería Brigiaecium. A la vez, los citados testimonios de origo sirven, indirectamente, para reafirmar la condición jurídico-administrativa de civitas/ciudad para Brigaecium, pues como he justificado en otra ocasión, la expresión de la origo -en sentido técnico- en la estructura onomástica es un indicador válido para identificar las antiguas ciudades/civitates romanas ${ }^{11}$.

En cuanto a su identificación geográfica, gracias a la información contenida en los antiguos itinerarios sabemos que estaba situada, según el Itinerario de Antonino, a 40 millas al S-SE de Asturica Augusta. Esto orienta a buscarla en pleno valle de Esla, en el área en torno a Benavente (Zamora), en la zona donde confluyen varios de sus afluentes: el Cea, primero y por la izquierda; el Órbigo y el Tera, después y por la derecha. En atención a estas informaciones y en función al trazado que se le dé a la vía romana, los investigadores han presentado variadas propuestas en esta comarca zamorana, entre las que destacan: la propia Benavente, El Peñón de Villabrázaro, la Dehesa de Morales de Fuentes de Ropel y, algo más alejada al oriente, Valderas, ya en la provincia de León ${ }^{12}$. Por mi parte, al igual que la mayoría de los autores que

5 439.8: Briceco y 440.1: Brigeco.

6 319.1: Brigicon.

7 3.3: Brigecio. Las dudas sobre la autenticidad de este documento epigráfico excepcional han sido despejadas definitivamente: FERNÁNDEZ OCHOA, C., MORILLO CERDÁN, A., GIL SENDINO, F. (2012): "El Itinerario de Barro. Cuestiones de autenticidad y lectura", Zephyrus, 70, pp. 151-179.

8 Es improbable la vinculación con Brigaecium de un individuo nombrado en una inscripción de Crémenes ( $\mathrm{HEpOl}$ 19268: Amparamo Brigetino), pues son muy frecuentes los topónimos formados a partir del radical brig-. En cuanto a un legionario veterano fallecido en Astorga, del que en ocasiones se ha sugerido su procedencia de Brigaecium (vid. en última instancia, SANTOS, N. (2011). "Soldados legionarios de origen astur en el ejército romano". Stvdia Zamorensia, 10, pp. 204-205) es seguro que era de Bracara Augusta (HEpOl 8450).

9 HEpOl 14387.

${ }^{10}$ HEPOl 12440.

${ }^{11}$ MARTINO GARCÍA, D. (2004). Las ciudades romanas de la Meseta Norte: identificación, estatuto jurídico y oligarquías (ss. I-III d. C.). Madrid: UCM e-prints, pp. 22-26.

12 MAÑANES, T. Y SOLANA, J.M. (1985). Ciudades y vías romanas en la cuenca del Duero (Castilla-León), Valladolid: Universidad de Valladolid, pp. 37-38; TOVAR, A. (1989). Iberische Landeskunde. Las tribus y las 
se han ocupado del tema en fechas recientes, me inclino por situar Brigaecium en el yacimiento de la Dehesa de Morales de las Cuevas. Es cierto que en sentido estricto no se puede considerar una identificación irrefutable, pero sí que es la opción más plausible en atención a la ubicación y a las características claramente urbanas, como veremos infra, de este gran yacimiento.

\section{BIBLIOGRAFÍA SOBRE LOS ESTUDIOS ARQUEOLÓGICOS EN LA DEHESA DE MORALES}

No es aventurado afirmar que los estudios arqueológicos de carácter científico sobre los terrenos de labor adyacentes al caserío de la Dehesa de Morales están cerca de cumplir ya su primer centenario, si aceptamos como tal el trabajo de inspección y prospección arqueológica llevada a cabo por los seminaristas que ayudaron al Padre Merino en su investigación sobre la Prehistoria y la Antigüedad de Tierra de Campos. Pese a que todo parece indicar que don Eugenio Merino no llegó a visitar el lugar, pues sus excursiones arqueológicas se limitaron a los lugares más próximos a Valderas, población donde ejercía el magisterio como Catedrático de Historia Eclesiástica y Arqueología del Seminario de San Mateo, la cantidad y calidad de los materiales romanos por él acumulados gracias a las aportaciones de sus alumnos seminaristas, de los párrocos y de los vecinos de la comarca, le llevó a afirmar en el informe que envió a la Real Academia de la Historia, fechado el 22 de junio de 1922, que este era un yacimiento "romano-prehistórico de lo más importante", uno de los cuatro más destacados en esta comarca ${ }^{13}$. El posterior análisis y estudio de esta variada y amplia colección arqueológica avala, sin duda, esta impresión ${ }^{14}$.

Décadas después, Virgilio Sevillano, que recorrió el lugar en 1961 y 1966, enriqueció el conjunto arqueológico recuperado en la Dehesa de Morales dando a conocer nuevos materiales de la Edad del Hierro y de época romana, principalmente unas interesantes marcas sobre ladrillos altoimperiales, ofreciendo al tiempo otras informaciones varias que resaltan la relevancia del yacimiento ${ }^{15}$. Sin embargo, no ha

ciudades de la antigua Hispania, Tomo 3: Tarraconensis. Baden-Baden: Verlag Valentin Koerner, pp. 324-325; PÉREZ MENCÍA, E. (1994-1995). "Brigecio". Brigecio. Revista de estudios de Benavente y sus tierras, 4-5, pp. 79-87; MARTINO GARCÍA, D. (2015) "Apuntes sobre Brigaecium de los Astures: hacia un modelo de la ciudad hispanorromana de la cuenca media del Duero”, Oppidum. Cuadernos de investigación, 11, pp. 82-83.

${ }^{13}$ MERINO, E. (1923). “Civilización romana y prerromana en Tierra de Campos”. Boletín de la Real Academia de la Historia, 83, pp. 32-33.

14 DELIBES, G. (1975). Colección arqueológica «Don Eugenio Merino» de Tierra de Campos (Colección "Fuentes y estudios de Historia leonesa” $\left.n^{\circ} 14\right)$. León, pp. 206-220.

15 SEVILlanO, V. (1967). “Tégulas romanas de la provincia de Zamora”. Archivo Español de Arqueología, 40, p. 
sido hasta el último cuarto del siglo pasado cuando se han efectuado los principales trabajos arqueológicos. Por una parte, los profesores Ricardo Martín Valls y Germán Delibes prospectaron en varias ocasiones este sitio publicando sus hallazgos en una serie de artículos ${ }^{16}$. Los extraordinarios hallazgos les permitieron reafirmar su importancia así como definir una ocupación continua desde la II Edad del Hierro hasta época bajoimperial. Por otra parte, en el año 1984 se realizó por primera vez una excavación arqueológica en el lugar, dirigida por Jorge Juan Fernández y con la participación de F. Regueras, J.R. López Rodríguez y J. Celis, y cuya publicación vio la luz poco tiempo después ${ }^{17}$. Con el fin de establecer una secuencia estratigráfica, en la citada campaña se efectuaron dos sondeos en dos áreas distintas y se añadió una prospección sistemática in extenso que abarcó toda la superficie en la que se tenía noticia de hallazgos en superficie con la intención de delimitar las distintas áreas ocupadas en cada periodo histórico, intentando a la vez determinar su posible función. Finalmente, desde los planteamientos de la arqueología aérea, Julio del Olmo realizó entre 1991 y 1995 varias campañas primaverales en las que se sobrevoló todo el yacimiento tomando una serie de fotografías muy elocuentes ${ }^{18}$. Estas fotografías han servido para identificar una parte muy significativa de la trama urbana así como varios edificios singulares de época romana, al tiempo que se confirmaba la zonificación propuesta en la prospección sistemática de julio de 1984.

Según mis informaciones, no se han realizado más intervenciones arqueológicas en los últimos 20 años, de manera que el conocimiento del urbanismo de la antigua ciudad que ocupó el solar de la actual Dehesa de Morales debe cimentarse sobre la conjunción de la información aportada por los hallazgos fortuitos y las prospecciones realizadas de manera intermitente a lo largo de la última centuria, más los resultados de los dos sondeos arqueológicos de 1984 y las elocuentes fotografías aéreas tomadas en

151; Idem. (1978). Testimonio arqueológico de la provincia de Zamora. Zamora: Ediciones Monte Casino, pp. 119-122.

${ }^{16}$ MARTÍN VALLS R. y DELIBES, G. (1975). "Hallazgos arqueológicos en la provincia de Zamora (II)”, Boletín del Seminario de Estudios de Arte y Arqueología, 40-41, pp. 455-458; Idem. (1976). "Hallazgos arqueológicos en la provincia de Zamora (III), Boletín del Seminario de Estudios de Arte y Arqueología, 42, pp. 417-420; Idem. (1978). "Hallazgos arqueológicos en la provincia de Zamora (V), Boletín del Seminario de Estudios de Arte y Arqueología, 44, pp. 328-334; Idem. (1979). "Hallazgos arqueológicos en la provincia de Zamora (VI)", Boletín del Seminario de Estudios de Arte y Arqueología, 45, pp.142-147.

17 CELIS J. (1990). “Apuntes para el estudio de la secuencia ocupacional de la «Dehesa de Morales», de Fuentes de Ropel, Zamora”. Actas del I Congreso de Historia de Zamora, vol. 2. Prehistoria y Edad Antigua, Zamora, pp. 467495.

18 OLMO, J. del (1996). “Arqueología aérea en la Dehesa de Morales”. Brigecio. Revista de estudios de Benavente y sus tierras, 6, pp. 57-74; Idem. (2006). “Arqueología aérea de las ciudades romanas de la Meseta Norte. Algunos ejemplos de la primera Edad del Hierro, segunda Edad del Hierro y Romanización”, en I. Moreno (coord.). Nuevos elementos de ingeniería romana: III Congreso de las Obras Públicas Romanas, León, pp. 321-324. 
los años 90 del siglo pasado. Todo ello permite, como veremos en las siguientes líneas, plantear una visión de conjunto sobre el urbanismo de la ciudad tanto para tiempos prerromanos como durante el Alto Imperio.

\section{BRIGAECIUM ANTES DE LA DOMINACIÓN ROMANA: UN VERDADERO OPPIDUM}

Es muy conocido por los especialistas, y aun por el público culto, que la población de Brigaecium se vio inmersa en la guerra que Augusto emprendió para someter los últimos territorios de la Península Ibérica que permanecían libres de la dominación romana. En efecto, contamos con un pasaje muy ilustrativo en las narraciones de Floro ${ }^{19}$ y Orosio ${ }^{20}$ relativas al Bellum Asturicum en las que se cuenta cómo en el año 25 a.C. los Brigaecini avisaron a los romanos del ataque que habían preparado los astures para sorprenderlos. De hecho, según Floro, los astures "descendieron de sus montañas nevadas" (a montibus niueis descenderant) y acamparon junto al río Astura para atacar simultáneamente con tres columnas a tres campamentos romanos, pero la delación de los Brigaecini permitió reaccionar al legado Publio Carisio y desbaratar el plan. Dejando al margen los interrogantes que persisten en este relato, como, por ejemplo, la identificación de esos tres campamentos romanos para sus tres legiones, lo que ahora interesa determinar es qué entidad tenía Brigaecium como núcleo de población en los tiempos de la conquista romana.

Los estudios arqueológicos han revelado que en el área de los astures el fenómeno urbano a la llegada de Roma era algo excepcional, al igual que sucedía con los otros pueblos montañeses del norte y noroeste de Hispania. Sin ánimo de ser exhaustivos y tomando como base algunos trabajos recientes que recogen la abundante bibliografía acerca del modelo de poblamiento de la II Edad del Hierro en esta zona ${ }^{21}$, se puede afirmar, en términos generales y admitiendo cierta diversidad regional -cada vez más evidente en los estudios arqueológicos recientes-, que el modelo de poblamiento predominante era el constituido por pequeños poblados, los llamados castros, ubicados en lugares elevados y escarpados y dotados de una muralla y otros variados sistemas

\footnotetext{
19 2.33.54-56.

$206.21 .9-10$.

${ }^{21}$ SASTRE, I. (2004). "Los procesos de la complejidad social en el noroeste peninsular: arqueología y fuentes literarias", Trabajos de Prehistoria, 61(2), pp. 99-110; GONZÁLEZ ÁLVAREZ, D. (2011). "De la cultura castreña al mosaico castreño: una aproximación en términos sociales a la variabilidad de las formas de poblamiento de las comunidades castreñas del noroeste peninsular y orla cantábrica", Estrat Crític, 5(1), pp. 213-226; FANJUL, A. (2014). Los astures y el poblamiento castreño en Asturias, (Tesis doctoral, Universidad Autónoma de Madrid).
} 
que facilitaban su defensa. Se trata de un modelo constituido por múltiples castros repartidos por el territorio y para el que se considera, mayoritariamente, que no existía una jerarquización del poblamiento. Así, cada castro controlaba un pequeño territorio, era autosuficiente $\mathrm{y}$, al parecer, independiente de los demás. Es este un modelo de poblamiento radicalmente opuesto al modelo jerarquizado presente en otras áreas peninsulares en el que existe un núcleo central, de mayores dimensiones y características urbanas que actúa como cabecera y centro de poder sobre un espacio en el que se ubican otros núcleos menores dependientes. El modelo de los castros, por otra parte, se adapta muy bien a las condiciones orográficas de esta parte de la Península Ibérica, una zona montañosa y muy compartimentada que facilita la enorme dispersión de la población y, por lo mismo, no favorece la formación de grandes aglomeraciones.

Ahora bien, los astures en la Antigüedad ocupaban un espacio que excedía con mucho las montañas de la cordillera Cantábrica y los Montes de León. De hecho, la propia denominación de Astures, en principio y desde la óptica romana, pienso que alude claramente a los que habitaban más allá del río Astura, el actual Esla. En efecto, todas las tierras bañadas por los afluentes del Duero situadas al oeste de este gran río, formaban parte de la antigua Asturia y estuvieron integradas en la unidad administrativa conocida como conventus Asturum de época romana altoimperial ${ }^{22}$. Es más, esta parte se conocía, según refiere el mismo Plinioo ${ }^{23}$, como la habitada por los Astures Augustani, en contraposición a la poblada por los Astures Transmontani, los de más allá de las montañas. Morfológicamente estas tierras se engloban dentro de la cuenca sedimentaria del río Duero, forman parte, por tanto, de la Meseta Norte. Brigaecium, precisamente, está situada aquí, en la ribera del Esla, en el mismo extremo sureste del antiguo territorio de los Astures.

El modelo de poblamiento de los últimos siglos del Primer Milenio antes de nuestra Era en la cuenca sedimentaria del Duero es muy distinto al referido de los castros. Los numerosos estudios arqueológicos en esta área, ocupada fundamentalmente por los vacceos, efectuados en las últimas décadas han permitido ofrecer una síntesis sobre su estructura de poblamiento ${ }^{24}$. Se trata de un modelo concentrado en grandes poblados, los oppida, que ubicados en las zonas más productivas, controlaban un amplio territorio bien definido y estaban muy distantes unos de otros. Así mismo, cada oppidum ocupaba una extensa superficie, normalmente mayor de 10 hectáreas (aunque

\footnotetext{
${ }^{22}$ Plinio, Nat. Hist., 3.18.

${ }^{23}$ Nat. Hist., 3.28.

${ }^{24}$ SACRISTÁN, J.D. (2011). "El poblamiento y el urbanismo vacceos". En Romero, F. y Sanz, C. (eds.). De la Región Vaccea a la arqueología vaccea, Valladolid, pp. 123-162.
} 
no son raros los que superan las 25 e incluso llegan a 40 hectáreas), estaba provisto de murallas, de una trama urbana ordenada y contaba con una población estimada, cuando menos, entre 1.500-2.000 habitantes. De todo ello, se concluye que estos grandes oppida eran entidades políticas independientes; eran, por tanto, auténticas ciudadesestado. En cuanto a Brigaecium, como veremos infra, y al igual que otros poblados de los astures de la misma zona meseteña, como Lancia (Villasabariego, León) o Bedunia (San Martín de Torres, León), responde al modelo de poblamiento concentrado en torno a un gran oppidum. Parece claro, por tanto, que la parte meridional de los astures, la que se asienta sobre las llanuras del Esla y sus afluentes y en la misma vecindad de los vacceos se asemeja al modelo de poblamiento descrito para los oppida vacceos, si bien con la particularidad de que en esta parte más occidental este modelo "vacceo" presenta junto al gran oppidum una serie de aldeas o poblados menores dependientes repartidos por el territorio, algo ciertamente distinto al modelo definido para el corazón del territorio vacceo en el que se identifican unas grandes ciudades muy distantes entre ellas sin aldeas dependientes, en lo que fue calificado en su día por J. D. Sacristán como los "vacíos vacceos". Veamos a continuación cual es el estado actual de conocimientos sobre el oppidum prerromano de Brigaecium.

El yacimiento de la Dehesa de Morales, solar de la antigua Brigaecium, se sitúa casi al extremo de la horquilla del interfluvio Esla-Cea, desplegándose inmediato al norte del actual caserío de Morales de las Cuevas. La parte más alta del yacimiento, en la cota 760 m.s.n.m., se eleva unos 50-55 metros por encima del cauce del Esla, al oeste, con un gran escarpe. Con respecto al Cea, que discurre al oriente, el escarpe es mucho menor, descendiendo la ladera de forma muy suave. En cuanto a su extensión, según los resultados de las prospecciones, serían, al menos, unas 10 hectáreas, lo que daría una población estimada de alrededor de 2.800 habitantes. Estas magnitudes remiten, sin duda, a los de un auténtico oppidum, a una verdadera aglomeración urbana, tal como he defendido en otra ocasión ${ }^{25}$.

Por los datos disponibles en la actualidad, no está clara su ocupación durante el Hierro I, pero sí que parece muy probable su existencia ya en el siglo IV a.C. ${ }^{26}$, siendo muy abundantes los restos datables en los siglos II-I a.C. Se han identificado claramente tres cenizales en la parte oriental del yacimiento y hay indicios de alguno más. De uno de estos cenizales se ha documentado su estratigrafía, se trata del vertedero o cenizal identificado en el sector (B) de la excavación de 1984, con una potencia de 2,3 m. y

${ }^{25}$ MARTINO GARCÍA, D. (2015). “Apuntes sobre Brigaecium de los Astures...”, op.cit., p. 87.

${ }^{26}$ CELIS, J. (1990). “Apuntes para el estudio de la secuencia ocupacional...”, op.cit., p. 468. 
dividido en ocho niveles ${ }^{27}$. Como es bien conocido, son muy frecuentes estos cenizales en los yacimientos meseteños durante la última fase de la Edad del Hierro (Fig. 1).

Del urbanismo prerromano, aparte de la extensión del oppidum y de la identificación de los citados cenizales, nada más se puede asegurar, a la luz de los datos disponibles. Ahora bien, me parece que se pueden presentar hipótesis de trabajo sobre la trama urbana, las murallas y los accesos al oppidum.

Las fotografías aéreas han logrado identificar gran parte de la trama urbana de la parte más alta del yacimiento, la que se corresponde con la ocupada en tiempos prerromanos, según han demostrado las prospecciones. Estas fotos muestran una disposición en torno a una calle longitudinal de norte a sur y hasta 12 calles transversales que la cortan en sentido este-oeste. Las calles tienen una anchura de 4 metros y están separadas entre sí por un espacio que oscila entre 25 y 35 metros. Entre la calles se aprecian algunas construcciones divididas en estancias de 2 a 6 metros de lado $^{28}$. Es cierto que carecemos por completo de datos sobre las estructuras del poblado prerromano. No se han excavado ni las viviendas, ni las calles del oppidum prerromano. Ahora bien, teniendo en cuenta que sabemos que la ciudad colaboró con los romanos durante la guerra de conquista (vid. supra), hemos de suponer que no fue arrasada y, por ello, es plausible plantear como hipótesis de trabajo que el trazado de la ciudad prerromana ha quedado fosilizado en época romana, de lo que serían prueba las fotos aéreas. Desde luego, la disposición de la calle longitudinal y las otras transversales remite sin duda a modelos indígenas, bien documentados en ciudades como Numancia y otras meseteñas del ámbito vacceo, tales como Pintia y Viminacium, o los oppida de Palenzuela y Las Quintanas de Valoria la Buena ${ }^{29}$.

\footnotetext{
${ }^{27}$ Ibid., pp. 472-475.

${ }^{28}$ OLMO, J. DEL (1996). “Arqueología aérea en la Dehesa...”, op.cit., pp. 59-61; Id. (2006). “Arqueología aérea de las ciudades romanas...”, op.cit., pp. 315 y 321-323.

29 OLMO, J. DEL (1999). “Arqueología aérea en tres ciudades indígenas romanizadas”. Los orígenes de la ciudad en el Noroeste Hispánico. Actas del Congreso Internacional (Lugo, 15-18 de mayo de 1996), Lugo, pp. 409-428; SACRISTÁN, J.D. (2011). "El poblamiento y el urbanismo...”, op.cit., pp. 192-196.
} 


\section{Figura 1. EL OPPIDUM PRERROMANO}

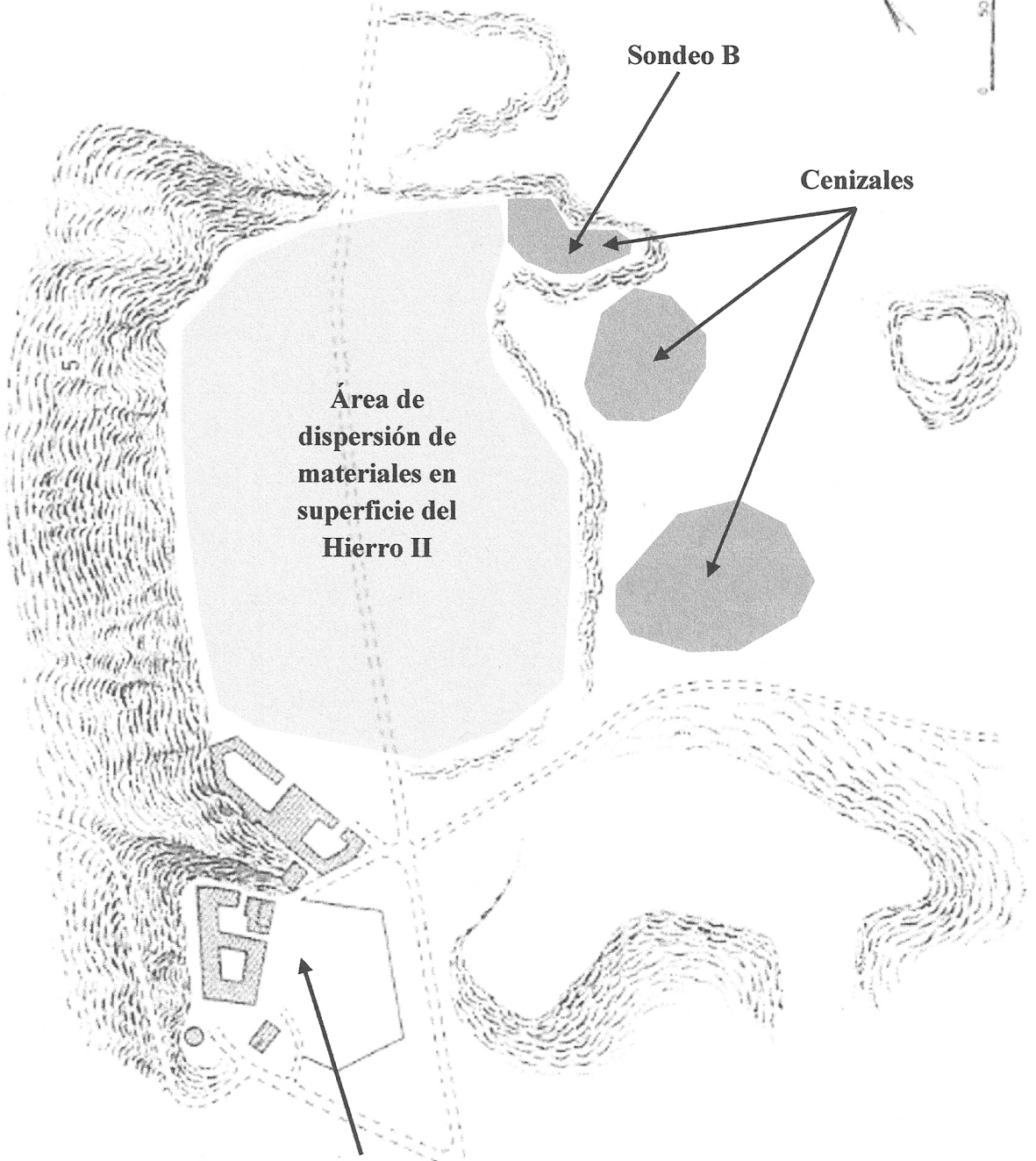

Caserío actual

Fig. 1: El Oppidum prerromano 
Otro de los aspectos relativos al urbanismo de la ciudad prerromana que no ha sido tratado con detenimiento es el del sistema defensivo, es decir, el análisis de las murallas y, eventualmente, otros elementos defensivos, que, como cualquiera de los oppida de la zona, debía tener. Aunque algunos investigadores ya señalaron la posibilidad de que el oppidum de alguna forma estuviese amurallado ${ }^{30}$, lo cierto es que hasta el momento no se ha detectado ningún indicio sobre el sistema defensivo, ni en las fotografías aéreas ni por otros restos arqueológicos. Pero en todo caso, parece bastante razonable suponer que todo el recinto más alto y elevado del yacimiento, que precisamente coincide con la zona de mayor concentración de materiales del Hierro II, estuviese rodeado por una muralla, dejando fuera los cenizales. La propia topografía actual, pese a lo arrasado y modificado del terreno por el continuo laboreo agrícola, orientan a buscar por aquí el trazado de la misma, tal como se puede observar en la propuesta de trazado que ahora presento (Fig. 2).

Conocemos bastante bien las murallas y sistemas defensivos de los poblados de los astures en los momentos precedentes y contemporáneos a la llegada de los romanos. Aunque existen múltiples estudios acerca de los recintos amurallados construidos en piedra, baste citar ahora solamente un buen ejemplo cercano, como es el castro de Las Labradas (Arrabalde, Zamora). Su sistema defensivo consta de una muralla realizada con cuarcitas y pizarras de alrededor de 1.500 metros lineales que junto a los roquedos y escarpes naturales configuran un perímetro total de 2.500 metros, dividió en dos recintos, uno interior y otro exterior, que en total cierran un espacio de 23 hectáreas ${ }^{31}$. También se han identificado murallas en plena cuenca sedimentaria del Duero, entre los vacceos, cuyos oppida, ya hemos visto que son muy semejantes a la Dehesa de Morales. Por ejemplo, la fotografía aérea ha detectado el trazado de la muralla en Castrogeriz (Burgos), Palenzuela (Palencia) y en las vallisoletanas Valoria la Buena, Tiedra y Padilla de Duero ${ }^{32}$. En esta última, identificada con la antigua ciudad de Pintia, se han sacado a la luz, gracias a varias excavaciones realizadas desde 2009, los restos de una potente muralla de unos 7 metros de ancho, construida con sillares de caliza en su cara externa, mientras que por la cara vista interna fue levantada utilizando adobes $^{33}$.

\footnotetext{
${ }^{30}$ OLMO, J. DEL (1996). Arqueología aérea en la Dehesa...”, op.cit., p. 62.

${ }^{31}$ MISIEGO, J.C. et alii, (2015). "El castro de Las Labradas (Arrabalde, Zamora): un ejemplo excepcional de la defensa de un territorio ante la amenaza de Roma”. En Rodríguez, O., Portilla, R., Sastre, J.C. y Fuentes, P. (coords). Fortificaciones en la Edad del Hierro. Control de los recursos y el territorio, Valladolid: Glyphos Publicaciones, pp. 484-487.

32 OLMO, J. DEL (2006). “Arqueología aérea de las ciudades romanas...”, op.cit., pp. 313-340.

33 SANZ, C., ROMERO, F., OLTEANU, T., GÓRRIZ, C. y PABLO, R. DE, (2010). "Los sistemas defensivos de Pintia". Vaccea, Anuario 2009, número 3. Valladolid: Edita Centro de Estudios Vacceos "Federico Wattenberg"
} 


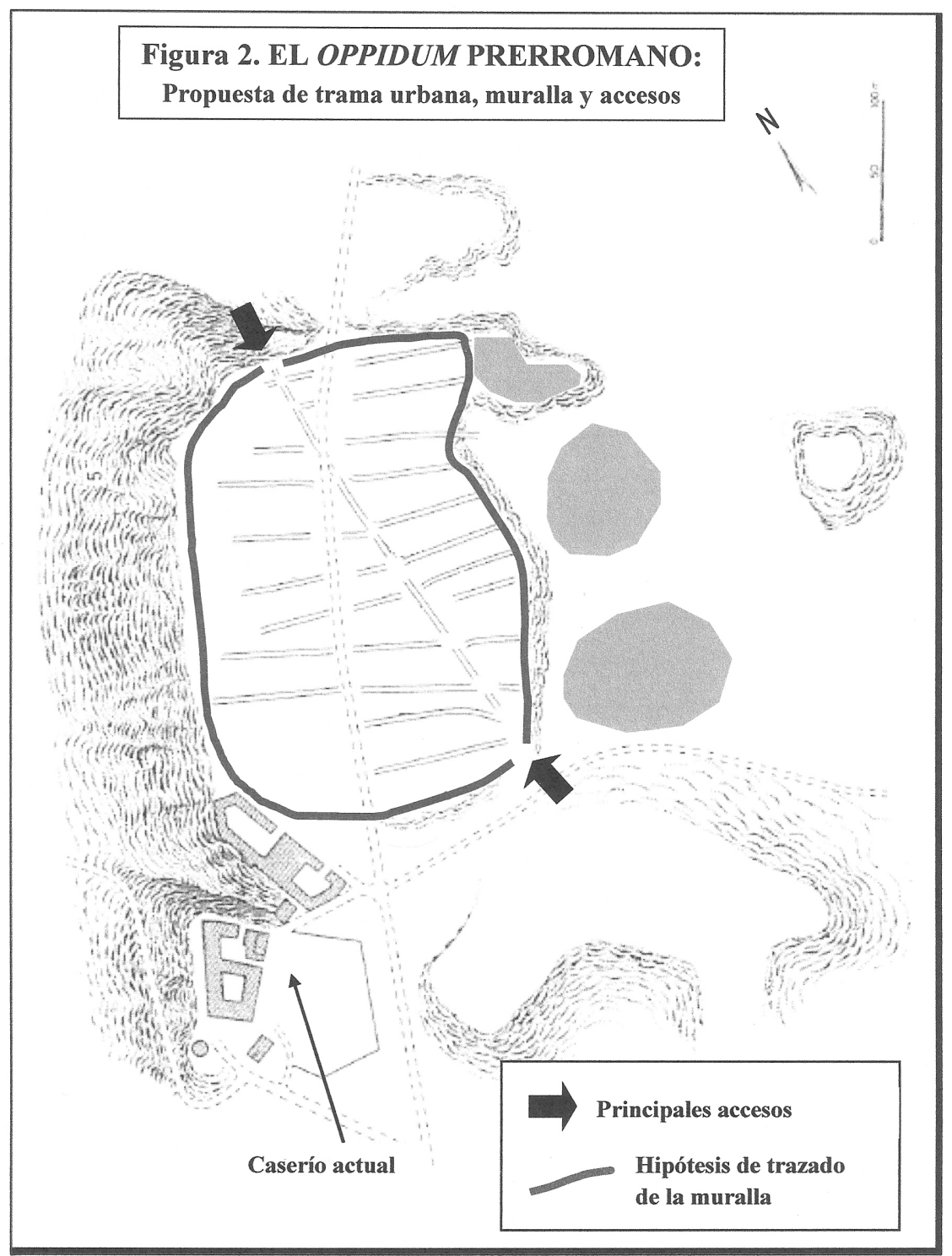

Fig. 2: El Oppidum prerromano. Propuesta de trama urbana, muralla y accesos.

(Universidad de Valladolid), pp. 13-19; SANZ, C., ROMERO, F., GÓRRIZ, C. y PABLO, R. DE, (2011). “E1 foso y el sistema defensivo de Pintia (Padilla de Duero/Peñafiel, Valladolid). Revista d'Arqueologia de Ponent 21, pp. 223-227; SANZ, C., ROMERO, F., GÓRRIZ, C. y PABLO, R. DE, (2014). "El complejo defensivo de Pintia (Padilla de Duero/Peñafiel, Valladolid)". En VII Simposio sobre los celtíberos. Nuevos Hallazgos, Nuevas Interpretaciones. Teruel, pp. 129-137. 
El sistema defensivo de Pintia se completaba con tres fosos sucesivos, separados entre sí por resaltes y estacadas ofreciendo un conjunto verdaderamente impresionante. Es más, según los resultados obtenidos en los últimos trabajos arqueológicos en el área vaccea, se confirma la existencia de murallas y complejos sistemas defensivos en muchas de sus ciudades ${ }^{34}$, entre las que destaca el descubrimiento reciente de parte de la muralla prerromana de Cauca (Coca, Segovia), que fue construida con adobes sobre una base de lajas de pizarra y cuarcita ${ }^{35}$. Sin embargo, como decía, en los terrenos de la Dehesa de Morales no hay el menor rastro de la muralla ni de otros elementos defensivos, lo que, descartando por completo la ausencia de muralla, me lleva a pensar en dos hipótesis explicativas.

En primer lugar, que se tratase de una muralla construida en piedra que está totalmente arrasada en la actualidad. No me parece plausible sostener que los restos de una supuesta muralla de piedra hayan desaparecido por completo, hasta sus mismos cimientos, bien sea por un derrumbe que los oculte por completo, o bien sea por acarreo de los materiales. Sospecho que la dificultad para identificar la muralla resida precisamente en los materiales empleados para su construcción. Quiero decir que la muralla de Brigaecium podía haber sido construida con materiales no pétreos, con materiales endebles que dejan muy poco rastro, tales como la madera y el barro. En este sentido, la utilización de adobes para la construcción de las murallas de Cauca y Pintia son un paralelo a tener en cuenta, sobre todo en zonas sedimentarias como la que nos ocupa donde escasea la piedra. Además, contamos con otros ejemplos de amurallamientos realizados a base de tapial y adobes en el mismo entorno geográfico de la Dehesa de Morales, en la comarca de Benavente y los Valles, si bien, estos ejemplos no son de época contemporánea. En efecto, para la I Edad del Hierro, en "La Corona/ El Pesadero" de Manganeses de la Polvorosa se ha documentado con mucha claridad una muralla levantada sobre un zócalo de piedras y/o tapial, cuyos paramentos externo e interno fueron construidos con adobes y en cuyo relleno se empleó tapial, tierra y algunas piedras ${ }^{36}$. Este poblado está situado al noroeste de la Dehesa de Morales, a una docena de kilómetros a vuelo de pájaro. Más cercano todavía, en la vecina localidad de

\footnotetext{
${ }^{34}$ ABARQUERO, F.J. y PÉREZ RODRÍGUEZ, F.J. (2015). "La aplicación de métodos geofísicos en la detección de sistemas defensivos vacceos: El caso de Paredes de Nava”. En Rodríguez, O. Portilla, R. Sastre, J.C. y Fuentes, P. (coords). Fortificaciones en la Edad del Hierro. Control de los recursos y el territorio. Valladolid: Glyphos Publicaciones, pp. 145-149.

${ }^{35}$ BLANCO GARCIA, J.F. (2015). "La muralla de Cauca Vaccea". Espacio, Tiempo y Forma. Serie I. Prehistoria y Arqueología, 8, pp. 87-134.

36 MISIEGO, J.C. et alii, (2013). Las excavaciones arqueológicas en el yacimiento de “La Corona/El Pesadero”, en Manganeses de la Polvorosa. La Edad del Hierro y la Época Romana en el norte de la provincia de Zamora (Memorias. Arqueología en Castilla y León $\left.n^{\circ} 19\right)$, Valladolid: Edita Junta de Castilla y León $<\underline{\text { http://patrimoniocultural.jcyl.es/ }}$ web/jcyl/PatrimonioCultural/es/Plantilla100Detalle/1284217306029/_/1284269010783/Redaccion>, pp. 207-214.
} 
Castrogonzalo, a menos de a 4 kilómetros al suroeste, existe constancia documental de la realización de unas obras de reparación de las fortificaciones del lugar a mediados del siglo XV, en la que se utilizaron fundamentalmente adobes y tapial ${ }^{37}$. Como puede verse, el empleo del adobe y/o tapial en la comarca de Benavente para la construcción de estructuras defensivas se remonta a tiempos protohistóricos y perdura hasta fines de la Edad Media, lo que no debe extrañar si tenemos en cuenta, como he señalado ya, la escasez de material lapídeo en esta comarca.

La utilización de materiales endebles como el adobe y el tapial en la construcción de las murallas durante la II Edad del Hierro, como hemos visto en Pintia y Cauca, así como en contextos geográficos y geológicos similares a los de la Dehesa de Morales puede servirnos perfectamente para justificar una hipótesis de trabajo como la que propongo: que la Brigaecium prerromana estaba defendida por una muralla que cerraba toda la parte superior del oppidum y que fue construida casi por completo con materiales endebles tales como los adobes, el tapial y la madera, completándola quizás con el empleo de una mínima cantidad de piedra. Esta propuesta se compadece bien con la ausencia de restos detectados por la fotografía aérea.

Del mismo modo que con la muralla, tampoco se han identificado en fotografía aérea o prospección los restos de las puertas de acceso al interior del oppidum. No obstante, la propia disposición de la trama urbana estructurada en torno a una larga calle longitudinal apunta a la existencia de, al menos, dos accesos principales, uno situado al extremo norte, sobre el mismo talud que cae hacia el río Esla, y el otro en el extremo sur, hacia la parte más llana ${ }^{38}$. Junto con esos dos accesos, parece razonable suponer otros en el lado oriental de la muralla, necesarios para dar un fácil acceso a los vertederos situados en esta zona. En este sentido, la segunda y, en especial, la tercera calle transversal (contadas desde el norte) parecen prolongarse y salir fuera del recinto del oppidum.

En resumen, la suma de los datos ya conocidos sobre la época prerromana y las hipótesis que acabo de presentar sobre la trama urbana, el trazado de la muralla y las puertas de acceso al interior, ofrecen una imagen de conjunto de La Dehesa de Morales como un gran oppidum muy similar a los otros ya conocidos en la cuenca media del Duero. Una verdadera urbe que ocupaba una extensión de unas 10 hectáreas, poblada por unos 2.800 habitantes y que podía funcionar perfectamente como el lugar central

${ }^{37}$ GONZÁLEZ RODRÍGUEZ, R. (2005). "La Mota de Castrogonzalo. Una fortificación terrera en el alfoz medieval de Benavente". Brigecio. Revista de estudios de Benavente y sus tierras, 15, pp. 79-103.

${ }^{38}$ Julio del Olmo consideró este último como el acceso principal: (1996). "Arqueología aérea en la Dehesa...”, op.cit., p. 62. 
de una auténtica ciudad-estado a la llegada de los romanos. Con todo, estas hipótesis de trabajo sólo se podrán validar o desechar necesariamente con nuevos estudios arqueológicos.

\section{DESARROLLO URBANO EN ÉPOCA ROMANA}

Para aproximarnos al conocimiento del urbanismo de Brigaecium en época romana altoimperial contamos con múltiples y variadas informaciones procedentes de tres metodologías arqueológicas distintas: la excavación, la prospección y la fotografía aérea.

Veamos en primer lugar los resultados de los dos sondeos efectuados durante la campaña de excavación de 1984, en la que se documentaron dos estructuras de época romana altoimperial: parte de unas termas y una dependencia doméstica dedicada a la molienda y almacenaje. En el sondeo A, realizado en la parte sur del yacimiento, pero dentro del área ocupada por el oppidum prerromano, se exhumaron varias estructuras que remiten sin duda a un espacio termal. En efecto, se sacó a la luz un hipocaustum y una pileta, interpretada como un alveus, que por sus dimensiones corresponderían a unas termas domésticas ${ }^{39}$. Su cronología es difícil de precisar, según el propio Jesús Celis, pero los pocos restos de cerámicas orientan a sostener una datación altoimperial, quizás de fines del siglo I o siglo II d.C.

En el otro sondeo, el B, situado en la parte noreste del oppidum se documentó una dependencia doméstica, al parecer destinada al almacenaje y la molienda dada la aparición de un molino de mano y de abundante cerámica (común romana, de tradición prerromana pintada, de "tradición indígena" y terra sigillata Hispanica). Allí se recogió también una interesante lucerna de canal abierto con la firma CASSI. Este conjunto se data fundamentalmente en la primera mitad del siglo II y no sobrepasa esa centuria $^{40}$. Por debajo de este primer nivel está el potente cenizal prerromano de los siglos II-I a.C. visto supra.

En cuanto a los resultados de las prospecciones, especialmente la minuciosa realizada en el mismo año 1984, se pueden resumir en tres ideas. En primer lugar, se notó una mayor abundancia de restos datados en el Alto Imperio, tanto cerámicos como constructivos (sillares, ladrillos, tegulae, etc.) en toda la zona sur del yacimiento, tanto en la parte intramuros como fuera de ella. En esta misma zona meridional, se

\footnotetext{
${ }^{39}$ CELIS J. (1990). “Apuntes para el estudio de la secuencia ocupacional...”, op.cit., pp. 469-470.

${ }^{40}$ Ibid., pp. 471-472.
} 
tiene noticia también de la aparición de suelos de opus signinum al realizar obras de reforma en el solar del actual caserío. En segundo lugar, se advierte con claridad una reducción del hábitat en tiempos bajoimperiales, restringiéndose los hallazgos a ciertos lugares de la parte más alta del yacimiento. Por último, cabe destacar que respecto a los cenizales del este, especialmente el situado más al sur, se nota una utilización a comienzos de la época altoimperial, dada la aparición de materiales de importación de fecha temprana como terra sigillata itálica (aretina) y sudgálica ${ }^{41}$.

Como se ve, las prospecciones ya ofrecieron una primera imagen de conjunto de la distribución espacial y cronológica, pero fueron las fotografías aéreas las que han logrado completar esta visión porque ampliaron nuestro conocimiento con la identificación, por un lado, de la trama urbana y, por otro, de múltiples edificios. A la vez, han resultado una información complementaria a lo que ya sabíamos por las prospecciones.

El trazado urbano reconocido por la fotografía aérea consta, como vimos ya, de una gran calle longitudinal que atraviesa de norte a sur toda la parte alta, la que se corresponde con el oppidum prerromano. En perpendicular a esta calle se disponen hasta otras 12 calles $^{42}$. Recordemos que se trata de la misma trama urbana que la propuesta para el oppidum prerromano, ya que a modo de hipótesis considero, como dije supra, que esta ha quedado fosilizada.

En el interior de las manzanas formadas por esta retícula de calles se aprecian algunos alineamientos que deben ser interpretados como muros. En la parte central, la unión de varios de estos muros, permite identificar una decena de estructuras rectangulares, algunas de ellas divididas entre dos y cuatro estancias de hasta seis metros de lado cada una ${ }^{43}$. Estos edificios parecen corresponder a viviendas, que suponemos reflejan el nivel arqueológico de época romana. La impresión general de este plano ordenado en una retícula con tendencia rectangular es que recuerda a los de otras ciudades de la Meseta Norte, tales como el muy bien conocido plano de Numantia, y también los de Viminacium o Pintia.

Fuera del área ocupada por el oppidum antiguo, se han detectado tres calles y los restos de hasta 10 edificios singulares de tipología romana, en lo que parece con meridiana claridad ser una ampliación de la ciudad que ocupa una extensión de más de 8 hectáreas. Una calle parte desde la puerta sur del oppidum amurallado y sigue un trazado hacia el norte que se adapta a las ondulaciones del terreno hasta que confluye

\footnotetext{
${ }^{41}$ Ibid., pp. 474-476.

${ }^{42}$ OLMO, J. DEL (1996). “Arqueología aérea en la Dehesa...”, op.cit., p. 60.

${ }^{43}$ Ibid., p. 62.
} 
con un ramal que sale como prolongación de la calle tercera. Al norte de ese cruce de calles se reconocen los restos de otra calle aislada que quizás sea la continuación de la calle que venía desde la puerta sur ${ }^{44}$. A ambos lados de esas calles se ubican los edificios, pero no siempre presentan una conexión clara con ellas (Fig. 3).

Resulta muy difícil la interpretación satisfactoria de cada uno de los diez edificios reconocidos en las fotografías aéreas, pues sólo en dos casos los restos detectados son lo suficientemente expresivos para que se pueda apreciar su articulación interna y de ahí proponer su identificación clara con algún modelo de construcción romana. Se trata de los edificios I y III, según la numeración de Julio del Olmo. Este arqueólogo propone que el edificio I, aun estando incompleto, responde al modelo canónico de casa romana de atrio, en este caso tetrástilo, suponiendo que el tablinum se situaba al norte y el acceso estaba en la fachada sur. En cuanto al III, sostiene que es un claro ejemplo de edificio de peristilo romano ${ }^{45}$.

De los demás edificios, otros cuatro (II, IV, VI y VII) han sido reconocidos con bastante amplitud y con una buena parte de sus elementos internos, pero según su descubridor, esto no es suficiente para establecer ante qué tipo de edificio nos encontramos. Por último, del resto (V, VIII, IX y X) sólo se puede decir que se trataría de partes de otras grandes construcciones ${ }^{46}$.

En resumen, la suma de los datos aportados por la prospección sistemática y las espectaculares fotografía aéreas muestran que estamos ante una ciudad que ocupaba una extensión de, al menos, 20-22 has cuyo plano urbano está dividido claramente en dos sectores, un llamado "barrio antiguo" que ocupaba la parte más alta de la urbe y que se corresponde exactamente con el oppidum prerromano y un nuevo barrio, o "ensanche altoimperial" que se fue extendiendo hacia el este, norte y sur, esto es, por todas las direcciones menos hacia el río Esla debido a que por aquí existe un pronunciado talud que impide la construcción. En dicho nuevo barrio se construyeron un gran número de edificios siguiendo los típicos modelos de la época, por más que las fotografías aéreas impidan determinar la naturaleza precisa de cada uno de ellos.

\footnotetext{
${ }^{44}$ Ibid., pp. 63-64.

${ }^{45}$ Ibid., pp. 64-65 y 73.

${ }^{46}$ Ibid., pp. 64-68.
} 


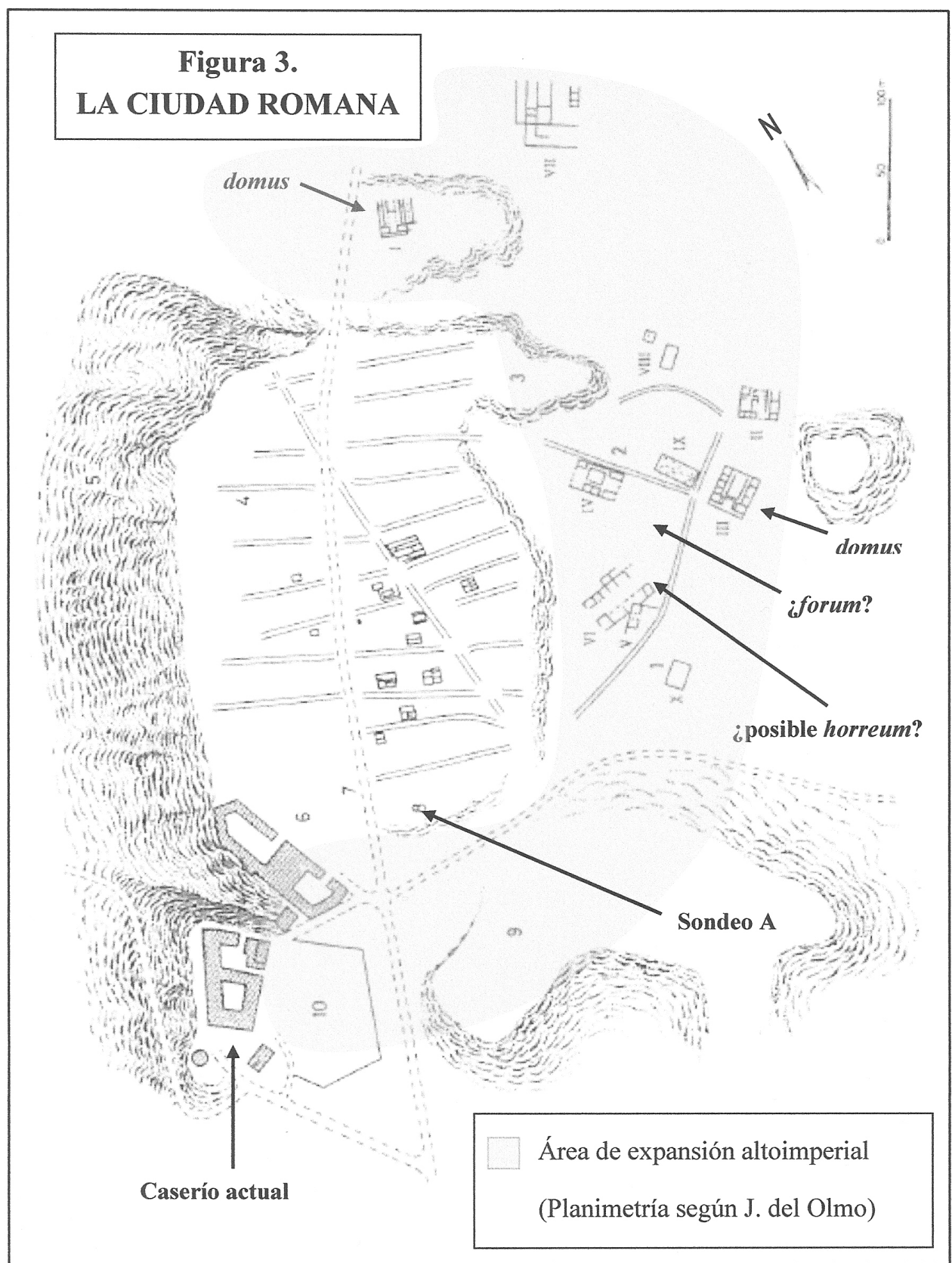

Fig. 3: La ciudad romana. 
A primera vista podría parecer que contamos con una imagen, si no completa, bastante aproximada de la planimetría de Brigaecium en época romana. Pero, a mi entender, permanecen todavía muchas cuestiones esenciales por resolver, como, entre otras, el problema del abastecimiento de agua, la identificación de las vías de acceso, la ubicación de las necrópolis o la identificación de los edificios públicos, así como toda la problemática relacionada con la cronología de la ampliación altoimperial. En las próximas líneas pretendo reflexionar y ofrecer algunas hipótesis sobre alguna de estas cuestiones.

En cuanto a la cronología de la ampliación, conscientes de que a fecha actual poseemos una información extremadamente parca, pienso que es razonable suponer que gran parte de estos edificios se levantaron, como pronto, en época flavia. Suposición que parte de la constatación de que muchas de estas construcciones están situadas encima de los antiguos cenizales del este, para los que se ha dicho que todavía siguieron usándose a comienzos del Alto Imperio ${ }^{47}$. Por lo demás, considerar que hubo una mayor actividad constructora en época flavia no desentona con la verdadera eclosión urbanística que recorre toda Hispania a partir de esta época como consecuencia de la concesión del ius Latii por Vespasiano y que tuvo, a escala local, el efecto de transformar muchas de las ciudades estipendiarias en ciudades privilegiadas, en municipios flavios. En este sentido, la documentación epigráfica permite sostener que Brigaecium fue uno de estos municipia Flavia ${ }^{48}$.

Cuestión mucho más compleja es abordar la identificación de los edificios detectados por fotografía aérea, pues, como ya hemos comentado, los restos impiden proponer una equivalencia razonable con alguno de los modelos romanos. Sin embargo, con los datos disponibles, me parece que los edificios I (casa de atrio) y III (casa de peristilo) muestran una planta muy elocuente, por lo que, pese a las reticencias de J. del Olmo, pienso que ambos deben calificarse como auténticas domus. Se trataría en ese caso de las domus propiedad de algunas de las principales familias de la oligarquía urbana, aquellas que regían el gobierno de este municipio flavio.

Si son pocos los rastros de edificaciones privadas, de las domus aristocráticas y de las viviendas ubicadas en el interior del oppidum -que presumiblemente pertenecían a las capas sociales más humildes-, menos todavía son los indicios sobre los edificios públicos. De hecho, la investigación no se ha ocupado de ellos. Ahora bien, partiendo de la base de que toda ciudad romana, entendida como comunidad política que ejerce las funciones de cabecera de administración local, que tenía capacidad de autogobierno

\footnotetext{
${ }^{47}$ CELIS J. (1990). “Apuntes para el estudio de la secuencia ocupacional...”, op.cit., p. 476.

${ }^{48}$ MARTINO GARCÍA, D. (2015). “Apuntes sobre Brigaecium de los Astures...”, op.cit., pp. 87-91.
} 
por medio de unos magistrados y un senado local, y que era centro económico y religioso de un territorio dependiente y, además, en el caso de Brigaecium, que disfrutó de la categoría de municipio flavio, no me parece razonable sostener que pese a ser una pequeña ciudad del interior de Hispania perteneciente a un pueblo, los astures, sometido en fechas tardías, careciese de algunos de los edificios públicos prototípicos de una ciudad romana, tales como los administrativos (curia, basilica), religiosos (templos), comerciales (tabernae, macellum) y de ocio (termas, teatro, anfiteatro). No quiero decir que se tuvieran que construir todos estos edificios, pero si es plausible esperar la presencia de algunos de ellos.

En este sentido, la recuperación de un fragmento epigráfico en bronce de un texto jurídico hallado en la Dehesa de Morales puede ser utilizada precisamente como un indicio de la presencia de edificios públicos. El documento en cuestión, el llamado Bronce de Fuentes de Ropel ${ }^{49}$, pese a la imposibilidad de una completa comprensión dado su estado tan fragmentario, contiene información interesantísima y excepcional relativa a un conflicto sobre los límites entre unos terrenos públicos, unos agri publici, y la supuesta propiedad de un particular de nombre Fronto. Estamos, por tanto ante una sentencia para delimitar un territorio, una limitatio agrorum, con el fin de resolver un litigio. Por desgracia, se ha perdido la parte en donde figuraban los magistrados responsables de dicha sentencia. Sin excluir del todo otras opciones, en vista de que el contenido conservado alude a terrenos situados dentro de los límites de la ciudad, parece que lo más razonable es sostener que fueron los propios magistrados locales, los IIviri iure dicundo, los que la emitieron.

Por la información contenida en los estatutos de las ciudades privilegiadas de Hispania sabemos que éstas contaban con archivos locales para depositar y custodiar los principales documentos públicos, las tabulae publicae, del municipium o la colonia $^{50}$. Así mismo, existen varios testimonios epigráficos del término tabularium para referirse al edificio que hacía la función de archivo, uno de los cuales procede de una ciudad de la provincia Bética, el municipio flavio de Munigua, tal como se documenta en una inscripción evergética ${ }^{51}$. Parece claro que esta denominación proviene de las tabulae ceratae que componían estos archivos. También sabemos de la existencia de los tabularia provinciales, en los que se custodiaba la documentación

\footnotetext{
${ }^{49}$ MAYER, M., GARCÍA, R. y ABÁSOLO, J. A. (1998). "El Bronce de Fuentes de Ropel”. Boletín del Seminario de Arte y Arqueología, 64, pp. 161-174. El documento está disponible en la base de datos online de Hispania Epigraphica,<eda-bea.es>, con el registro HEpOI 7310.

${ }^{50}$ RODRÍGUEZ NEILA, J.F. (2005). Tabulae Publicae: Archivos municipales y documentación financiera en las ciudades de la Bética, Madrid: Editorial Dykinson, pp. 17-23.

${ }^{51}$ HEpOl 5015.
} 
relativa a la administración provincial. Precisamente uno de los mejor documentados es el de la provincia Hispania citerior, a la que pertenecía Brigaecium, gracias a los diversos epígrafes que aluden a los funcionarios encargados del mismo, los tabularii, hallados en su capital, Tarraco ${ }^{52}$. En fin, aunque no contemos con muchos testimonios sobre los tabularia de las ciudades hispanas, es indudable su existencia incluso en pequeños municipios, tal como hemos visto en Munigua, por lo cual, me parece razonable proponer la existencia en Brigaecium de un edificio específico para archivo municipal, un auténtico tabularium, o si no, al menos, de una dependencia pública destinada a tal efecto, quizás aneja a la curia, o incluso que los documentos fueran depositados en un templo o la basilica, tal como ocurrió en la misma Roma y en otras ciudades del Imperio.

Es patente el papel indirecto que las fuentes epigráficas tienen en la identificación de los edificios públicos. La presencia de dedicaciones votivas, de epígrafes evergéticos y, eventualmente, de inscripciones funerarias cuyo contenido informe sobre esos edificios, pueden ser utilizados como indicios de la existencia de los mismos. Pero, desgraciadamente, el corpus epigráfico de la Dehesa de Morales se reduce exclusivamente al Bronce de Fuentes de Ropel. Efectivamente, no se ha recuperado ningún otro testimonio epigráfico en el yacimiento y las dos inscripciones que mencionan individuos procedentes de Brigaecium nada aportan al respecto.

Del mismo modo que cabe esperar la existencia de edificios públicos, también debía contar con un forum. A modo de mera hipótesis, sugiero la posibilidad de que esta plaza pública estuviera ubicada en la ampliación de la ciudad, fuera, por tanto del solar del antiguo oppidum. Me parece que el espacio libre que media entre los edificios III, IV y IX, precisamente junto a la intersección de las dos calles de la parte oriental, es un lugar céntrico y adecuado (Fig. 3). Por otro lado, cerca de este lugar, se ha identificado un edificio rectangular, el número VI, del que por las trazas conservadas me recuerda vagamente la planta de un horreum. En los últimos años, la investigación sobre estos graneros y/o almacenes de víveres ha progresado mucho ${ }^{53}$, conociéndose cada vez mejor los horrea rurales y urbanos de las Hispaniae; quizás aquí tenga un nuevo caso de estudio.

${ }^{52}$ OZCÁRIZ, P. (2014). Administración de la provincia Hispania citerior durante el Alto Imperio. Organización territorial, cargos y fiscalidad. Barcelona: Publicacions i edicions de la Universitat de Barcelona, pp. 249-251.

53 SALIDO, J. (2013). "El abastecimiento de grano a las ciudades hispanorromanas. Producción, almacenaje y gestión”. Archivo Español de Arqueología, 86, pp. 131-148. 


\section{A MODO DE CONCLUSIÓN}

Es indudable que en los pagos inmediatos al actual caserío de la Dehesa de Morales se levantó en la Antigüedad una auténtica ciudad. He afirmado, también, que esa ciudad no es otra que Brigaecium de los Astures. Acerca de su urbanismo tenemos una visión de conjunto gracias a los resultados de las diversas intervenciones arqueológicas sobre el lugar: prospecciones sistemáticas, dos pequeños sondeos y las espectaculares fotografías aéreas, así como múltiples hallazgos fortuitos. De todos ellos, se puede sintetizar que durante la época prerromana, en los siglos II-I a.C., este asentamiento era una verdadera ciudad, un oppidum de más de 10 hectáreas de extensión y unos 2.800 habitantes. De esta misma fase se han identificado varios cenizales en sus afueras, para uno de los cuáles se ha documentado su estratigrafía. Ya en época romana altoimperial, la ciudad creció hasta alcanzar unas 22 hectáreas de superficie. Para esta fase se ha identificado por fotografía aérea una parte significativa, aunque muy parcial, de su trazado urbano. Destaca la trama urbana de la parte correspondiente al oppidum prerromano en la que se identifica un trazado urbano casi completo en retícula y articulado en torno a una larga calle en sentido longitudinal norte-sur y otras doce transversales a esta, mostrando una estructura de tipo indígena similar al de otras ciudades de la cuenca del Duero. El plano urbano del antiguo oppidum parece que ha quedado fosilizado en la Brigaecium de época romana. Fuera de este espacio, en la ampliación altoimperial, se han detectado por fotografía aérea dos calles y hasta 10 grandes edificios, dos de los cuales concuerdan con una típica domus. A su vez, los sondeos efectuados en dos puntos de la zona alta del yacimiento, documentaron partes de unas termas domésticas y de otra estancia de almacenaje datadas ambas durante el Alto Imperio. Por último, las prospecciones confirman la ocupación bajoimperial pero reduciéndose su extensión y limitándose a la zona alta del yacimiento, precisamente la ocupada por el antiguo oppidum prerromano.

Como he dicho, tenemos una visión de conjunto, pero son todavía muchos los interrogantes que deben plantearse. Aquí he presentado algunas hipótesis: el trazado de la muralla del oppidum prerromano y los materiales con que fue construida; la existencia de edificios públicos, un posible tabularium, por ejemplo, o la ubicación del forum. Desde luego, son necesarias nuevas prospecciones sistemáticas, más aun en unos terrenos de labrantío removidos periódicamente en los que salen a superficie restos cerámicos y constructivos muy copiosos y variados. En este sentido, pudiera resultar provechoso probar la metodología de la prospección geofísica para identificar la muralla y los demás sistemas defensivos. Usando la técnica de la magnetometría 
de cesio se ha conseguido, en fechas muy recientes, la detección del potente sistema defensivo del oppidum vacceo de "La Ciudad" de Paredes de Nava (Palencia) ${ }^{54}$. También sería muy conveniente, por otra parte, realizar nuevos sondeos para establecer estratigrafías, determinar la naturaleza de los edificios detectados por fotografía aérea y contrastar, en su caso algunas de las hipótesis lanzadas en estas líneas.

En fin, han pasado ya más de 20 años desde la publicación de las fotografías aéreas de Julio del Olmo, que constituyen el último estudio específico sobre este gran yacimiento de la provincia de Zamora. Es hora ya, siguiendo a Don Quijote, de sacar a este yacimiento del "encanto" en que se encuentra prisionero. Esperemos que pronto se retomen los trabajos arqueológicos.

\section{ABREVIATURAS}

HEpOl Hispania Epigraphica on line database (http://eda-bea.es/)

Nat. His. C. Plinio, Naturalis Historia.

\section{BIBLIOGRAFÍA}

ABARQUERO, F.J. y PÉREZ RODRÍGUEZ, F.J. (2015). "La aplicación de métodos geofísicos en la detección de sistemas defensivos vacceos: El caso de Paredes de Nava". En Rodríguez, O., Portilla, R., Sastre, J.C., y Fuentes, P. (coords), Fortificaciones en la Edad del Hierro. Control de los recursos y el territorio, Valladolid: Glyphos Publicaciones, pp. 131-151.

BLANCO GARCIA, J.F. (2015). "La muralla de Cauca Vaccea". Espacio, Tiempo y Forma. Serie I. Prehistoria y Arqueología, 8, pp. 87-134.

CELIS, J. (1990). "Apuntes para el estudio de la secuencia ocupacional de la «Dehesa de Morales», de Fuentes de Ropel, Zamora". Actas del I Congreso de Historia de Zamora, vol. 2. Prehistoria y Edad Antigua, Zamora, pp. 467-495.

DELIBES, G. (1975). Colección arqueológica «Don Eugenio Merino» de Tierra de Campos (Colección "Fuentes y estudios de Historia leonesa" $n^{\circ}$ 14). León.

FANJUL, A. (2014). Los astures y el poblamiento castreño en Asturias. Tesis doctoral, Departamento de Prehistoria y Arqueología, Facultad de Geografía e Historia, Universidad Autónoma de Madrid.

FERNÁNDEZ OCHOA, C., MORILLO CERDÁN, A., GIL SENDINO, F. (2012): “El Itinerario de Barro. Cuestiones de autenticidad y lectura”, Zephyrus, 70, pp. 151-179

54 ABARQUERO, F.J. y PÉREZ RODRÍGUEZ, F.J. (2015). “La aplicación de métodos geofísicos en la detección...”, op.cit., pp. 131-151. 
GONZÁLEZ ÁLVAREZ, D. (2011). "De la cultura castreña al mosaico castreño: una aproximación en términos sociales a la variabilidad de las formas de poblamiento de las comunidades castreñas del noroeste peninsular y orla cantábrica”. Estrat Crític, 5(1), pp. 213-226.

GONZÁLEZ RODRÍGUEZ, R. (2005). "La Mota de Castrogonzalo. Una fortificación terrera en el alfoz medieval de Benavente". Brigecio. Revista de estudios de Benavente y sus tierras, 15 , pp. 79-103.

MAÑANES, T. y SOLANA, J.M. (1985). Ciudades y vías romanas en la cuenca del Duero (Castilla-León). Valladolid: Universidad de Valladolid.

MARTÍN VALLS, R. y DELIBES, G. (1975). "Hallazgos arqueológicos en la provincia de Zamora (II)". Boletín del Seminario de Estudios de Arte y Arqueología, 40-41, pp. 455-458.

MARTÍN VALLS, R. y DELIBES, G. (1976). "Hallazgos arqueológicos en la provincia de Zamora (III)”. Boletín del Seminario de Estudios de Arte y Arqueología, 42, pp. 411-440.

MARTÍN VALLS, R. y DELIBES, G. (1978). "Hallazgos arqueológicos en la provincia de Zamora (V)". Boletín del Seminario de Estudios de Arte y Arqueología, 44, pp. 321-346.

MARTÍN VALLS, R. y DELIBES, G. (1979). "Hallazgos arqueológicos en la provincia de Zamora (VI)". Boletín del Seminario de Estudios de Arte y Arqueología, 45, pp. 125-147.

MARTINO GARCÍA, D. (2004). Las ciudades romanas de la Meseta Norte: identificación, estatuto jurídico y oligarquías (ss. I-III d. C.), Madrid: UCM e-prints.

MARTINO GARCÍA, D. (2015). “Apuntes sobre Brigaecium de los Astures: hacia un modelo de la ciudad hispanorromana de la cuenca media del Duero". Oppidum. Cuadernos de investigación, 11, pp. 79-97.

MAYER, M., GARCÍA, R. y ABÁSOLO, J. A. (1998). "El Bronce de Fuentes de Ropel”. Boletín del Seminario de Arte y Arqueología, 64, pp. 161-174.

MERINO, E. (1923). “Civilización romana y prerromana en Tierra de Campos”. Boletín de la Real Academia de la Historia, 83, pp. 26-34.

MISIEGO, J.C., MARTÍN CARBAJO, M.A., MARCOS CONTRERAS, G.J., SANZ GARCÍA, F.J., PÉREZ RODRÍGUEZ, F.J., DOVAL, M., VILLANUEVA, L.A., SANDOVAL, A.M.a , REDONDO, R., OLLERO, F.J., GARCÍA RIVERO, P.F., GARCÍA MARTÍNEZ, M. ${ }^{a}{ }$. y SÁNCHEZ BONILLA, G., (2013). Las excavaciones arqueológicas en el yacimiento de "La Corona/El Pesadero", en Manganeses de la Polvorosa. La Edad del Hierro y la Época Romana en el norte de la provincia de Zamora (Memorias. Arqueología en Castilla y León $n^{\circ}$ 19). Valladolid: Edita Junta de Castilla y León, <http://patrimoniocultural.jcyl. es/web/jcyl/PatrimonioCultural/es/Plantilla100Detalle/1284217306029//1284269010783/ $\underline{\text { Redaccion> }}$.

MiSIEGO, J.C., SANZ, F.J., MARTÍN CARBAJO, M.A., MARCOS CONTRERAS, G.J. y DOVAL, M. (2015). "El castro de Las Labradas (Arrabalde, Zamora): un ejemplo excepcional de la defensa de un territorio ante la amenaza de Roma". En Rodríguez, O., Portilla, R., Sastre, J.C., y Fuentes, P. (coords). Fortificaciones en la Edad del Hierro. Control de los recursos y el territorio. Valladolis: Glyphos Publicaciones, pp. 479-498. 
OLMO, J. DEL (1996). “Arqueología aérea en la Dehesa de Morales”. Brigecio. Revista de estudios de Benavente y sus tierras, 6, pp. 57-74.

OLMO, J. DEL (1999). “Arqueología Aérea en tres ciudades indígenas romanizadas”, Los orígenes de la ciudad en el Noroeste Hispánico. Actas del Congreso Internacional (Lugo, 15-18 de mayo de 1996). Lugo, pp. 409-428.

OLMO, J. DEL (2006). "Arqueología aérea de las ciudades romanas de la Meseta Norte. Algunos ejemplos de la primera Edad del Hierro, segunda Edad del Hierro y Romanización". En I. Moreno (coord.). Nuevos elementos de ingeniería romana: III Congreso de las Obras Públicas Romanas, León, pp. 313-340.

OZCÁRIZ, P. (2014). Administración de la provincia Hispania citerior durante el Alto Imperio. Organización territorial, cargos y fiscalidad, Barcelona: Publicacions i edicions de la Universitat de Barcelona.

PÉREZ MENCIA, E. (1994-1995). "Brigecio". Brigecio. Revista de estudios de Benavente y sus tierras, 4-5, pp. 75-98.

RODRÍGUEZ NEILA, J.F. (2005). Tabulae Publicae: Archivos municipales y documentación financiera en las ciudades de la Bética, Madrid: Editorial Dykinson.

SACRISTÁN, J.D. (2011). "El poblamiento y el urbanismo vacceos”. En Romero, F. y Sanz, C. (eds.). De la Región Vaccea a la arqueología vaccea, Valladolid, pp. 123-162.

SALIDO, J. (2013). "El abastecimiento de grano a las ciudades hispanorromanas.

Producción, almacenaje y gestión”. Archivo Español de Arqueología, 86, pp. 131-148.

SANZ, C., ROMERO, F., OLTEANU, T., GÓRRIZ, C. y PABLO, R. DE, (2010). “Los sistemas defensivos de Pintia”. Vaccea, Anuario 2009, número 3, Valladolid: Edita Centro de Estudios Vacceos "Federico Wattenberg” (Universidad de Valladolid), pp. 13-19.

SANZ, C., ROMERO, F., GÓRRIZ, C. y PABLO, R. DE (2011). "El foso y el sistema defensivo de Pintia (Padilla de Duero/Peñafiel, Valladolid). Revista d'Arqueologia de Ponent 21, pp. 221-232.

SANZ, C., ROMERO, F., GÓRRIZ, C. y PABLO, R. DE (2014). "El complejo defensivo de Pintia (Padilla de Duero/Peñafiel, Valladolid)". En VII Simposio sobre los celtíberos. Nuevos Hallazgos, Nuevas Interpretaciones. Teruel, pp. 129-137.

SANTOS, N. (2011). "Soldados legionarios de origen astur en el ejército romano". Stvdia Zamorensia, 10, pp. 191-216.

SASTRE, I. (2004). "Los procesos de la complejidad social en el noroeste peninsular: arqueología y fuentes literarias”. Trabajos de Prehistoria, 61(2), pp. 99-110.

SEVILLANO, V. (1967). "Tégulas romanas de la provincia de Zamora”. Archivo Español de Arqueología, 40, pp. 151-154.

SEVILlANO, V. (1978). Testimonio arqueológico de la provincia de Zamora, Ediciones Monte Casino, Zamora.

TOVAR, A. (1989): Iberische Landeskunde. Las tribus y las ciudades de la antigua Hispania, Tomo 3: Tarraconensis, Baden-Baden: Verlag Valentin Koerner. 